\title{
The contrastive study of chemical treatment on the properties of hydrophobic PVDF membrane
}

\author{
Mohamad Fairus Rabuni ${ }^{1}$ \\ ${ }^{I}$ Department of Chemical Engineering, University of Malaya \\ ${ }^{l}$ Email:fairus_rabuni@yahoo.co.uk
}

\begin{abstract}
In this study, polyvinylidene fluoride (PVDF) flat membranes were treated with potassium hydroxide $(\mathrm{KOH})$, sodium hydroxide $(\mathrm{NaOH})$ and sodium hypochlorite $(\mathrm{NaOCl})$. The effects of temperature, treatment duration and chemical concentration towards the properties of PVDF membrane were contrastively studied. Following treatment, membrane became much brittle with a reduced nominal elongation to as low as $61 \%$. Temperature elevation and prolonged treatment time accelerated the chemical reaction with PVDF as shown by further decline in the membrane stability. Nevertheless, the treatment conditions employed in this study are considered too mild for the dehydrofluorination process to occur. FTIR analysis indicated no carbon-carbon double bond formation and DSC analysis showed insignificant changes in the melting temperature. All treated membrane was observed to have larger pore size as a result of stretching on surface structure. Comparatively, acquired results showed that $\mathrm{NaOCl}$ has the most detrimental impact on the PVDF membrane stability, followed by $\mathrm{NaOH}$ and $\mathrm{KOH}$.
\end{abstract}

Keywords: PVDF membrane, chemical resistance, stability, dehydrofluorination

\section{Introduction}

Membrane technology has attracted considerable attention not only from the research community, but also from the industrial sector to replace the conventional separation processes. This progressive evolution is mostly attributed to its simplicity, flexibility, cheaper cost and easier to operate. Besides, in accordance with great promotion of clean production and urgent demand on energy conservation, membrane technology appeared to be the best solutions to cater all those requirements. Since separation process is important in most industries, membrane technology offers a wide application margin in various industries such as water and wastewater treatment, chemical production, food and beverages as well as pharmaceutical. Membrane as the key component in membrane system must possess outstanding mechanical strength, thermal stability and chemical resistance, which depend on the material of construction.

Currently, PVDF is a semi crystalline polymer that has been widely used as a membrane material given by high mechanical and thermal stability as well as resists to a broad range of chemicals $[1,2]$. However, the noteworthy fact is that PVDF is conditionally suitable in an alkaline environment [3]. There are still many applications of PVDF membranes with alkaline solutions in practice without clear restriction such as during the cleaning of fouled membrane and in membrane contactor. Chemical cleaning is the common procedure executed to eliminate irreversible fouling where $\mathrm{NaOCl}$ is the most preferred considering its relatively low price and high efficiency. Meanwhile, a membrane contacting system with PVDF membrane for toxic gas removal commonly

Manuscript History:

Received 6 April, 2015, Revised 22 April, 2015, Accepted 23 April, 2015, Published 30 April, 2015

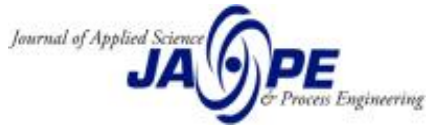


utilised $\mathrm{NaOH}$ aqueous solution as absorbent because of its higher separation performance [4-6]. Despite the successfulness of chemical cleaner to eliminate the fouling, the cleaning procedure should be minimised because repeated exposure to chemical may affect membrane lifespan, and thus results in its failure [7, 8]. Moreover, the compatibility between membrane materials with the employed chemicals should be inspected prior to the application in order to prevent membrane structural deterioration.

Exposure to the harsh chemical environment has long been suspected to be detrimental to PVDF. A number of works have reported the vulnerability of PVDF membrane towards alkaline environments, though their aim is to study the degradation mechanism [9-12]. It is essential to state that earlier studies were conducted either in the presence of a catalyst or by employing long-term exposure. So far, there is still a lack of the systematic study to demonstrate the impacts in real applications, which is caused by the mild conditions used during both chemical cleaning and membrane contactor purposes [13]. Moreover, degradation of polymer membrane due to hypochlorite cleaning has been reported in several papers [7, 14-16] but particular studies on PVDF membrane are surprisingly scarce. This could be attributed to information of high tolerance with oxidants as provided by the membrane manufacturers. Therefore, the main objective of this work is to perform a contrastive study on the effects of different chemicals on the properties of PVDF membrane. Three types of chemicals $(\mathrm{KOH}, \mathrm{NaOH}$, and $\mathrm{NaOCl})$ were used to treat hydrophobic PVDF membranes in various treatment conditions and all treated membranes were analysed and compared.

\section{Experimental section}

\subsection{Materials}

Commercial flat sheet, hydrophobic PVDF membrane with a pore size of $0.2 \mu \mathrm{m}$ was purchased from Sinoma Group, (China). $\mathrm{KOH}$ and $\mathrm{NaOH}$ (both in pellet form) were obtained from $\mathrm{R} \& \mathrm{M}$ Chemicals (Malaysia) and $\mathrm{NaOCl}$ solution of 4.00-4.99\% available chlorine was purchased from Sigma-Aldrich (Malaysia). Throughout this research, ultrapure water (Milli-Q) was used to prepare solutions and for rinsing purposes. Since $\mathrm{NaOCl}$ degrades with time, pocket colorimeter (Hach Company) was used to determine its concentration by the DPD Free Chlorine method prior to experimental works.

\subsection{Experimental works}

PVDF membranes were treated with various chemical concentrations, $0.01,0.1$ and $0.2 \mathrm{M}$ at different temperature, $25 \pm 2{ }^{\circ} \mathrm{C}$ (room temperature) and $45 \pm 2{ }^{\circ} \mathrm{C}$. The treatment time was varied, for 30 minutes and 180 minutes. Following the chemical treatment, the membranes were rinsed and stored in ultrapure water for around one hour to remove any residual chemical that remains in the membrane.

\subsection{Membrane characterisations}

The morphologies of membrane were examined using a field emission scanning electron microscope (FESEM) (Carl Zeiss Microscopy, USA). Prior to the analysis, the membrane was sputter coated with gold for 30 seconds using Leica EM SCD005 sputter coater. The membrane's mechanical strength was studied based on membrane elongation using tensile testing machine, Instron 4466 (Instron, USA) in accordance with ASTM D882. At a constant elongation velocity of $50 \mathrm{~mm} / \mathrm{min}$, the membrane with original gauge length of $12 \mathrm{~cm}$ was pulled at both ends. At least three measurements for a particular sample were determined to obtain the average value and standard deviation is less than 5\%. ASAP 2020 (Micromeritics, UK) was used to measure the specific surface area of membrane with 
the BET adsorption method. All samples were first degassed at $120{ }^{\circ} \mathrm{C}$ for 3 hours and then proceed for analysis.

The measurement of membrane melting point was done using differential scanning calorimetry equipment, DSC 1 (Mettler Toledo, Switzerland). The changes in membrane surface functional group are determined by FTIR in attenuated total reflectance (ATR) mode. All surface infrared spectra were obtained in the wavelength range of 650 to $4000 \mathrm{~cm}^{-1}$ using a Nicolet iS-10 spectrometer (Thermo Scientific, USA) by signal averaging 32 scans, set at $4 \mathrm{~cm}^{-1}$ resolution. Membrane water flux measurement was determined using a cross-flow membrane bench filtration unit TR 32 (Solteq, Malaysia), with a membrane effective area of approximately $41.0 \mathrm{~cm}^{2}$. Prior to testing, the membrane was soaked in ultrapure water for a day. The water flux is determined once the system reaches its steady state at which permeate rate is constant with time. To determine the degree of membrane hydrophobicity or hydrophilicity, contact angle measurement was done using the sessile drop method, with DataPhysics OCA-15 plus (DataPhysics, USA). Using a microsyringe, a $20 \mu \mathrm{L}$ drop of distilled water was positioned onto the surface of the membrane, and the air-water-surface contact angle was calculated within $10 \mathrm{~s}$. No less than five readings of contact angle were taken. Hydrophobic membrane exhibits a contact angle value more than $90^{\circ}$ while any value lower than that is considered as hydrophilic.

\section{Results and discussion}

\subsection{Morphology of PVDF membrane}

Since insignificant changes in the pore structure were observed when the membranes were treated using lower concentration, therefore only FESEM images of membranes treated in the most harsh condition $\left(0.2 \mathrm{M}\right.$ for 3 hours at $45^{\circ} \mathrm{C}$ ) were reported. The FESEM images (shown in Figure 1) are the membranes treated with $0.2 \mathrm{M}$ of chemical solutions at $45{ }^{\circ} \mathrm{C}$ for 3 hours. There were significant differences in membrane morphology before and after treatment as the pores are stretched/tore apart, resulting in a larger pore structure. In other word, the enlargement of pore size was clearly detected after membranes immersion in alkaline solutions. A different degree of destruction of membrane surface could be observed once the membrane was treated using different chemical. Membrane treated with either $\mathrm{NaOCl}$ or $\mathrm{NaOH}$ showed the most significant changes in pore structure while $\mathrm{KOH}$ treated membrane displayed a relatively less damage. 
(a)

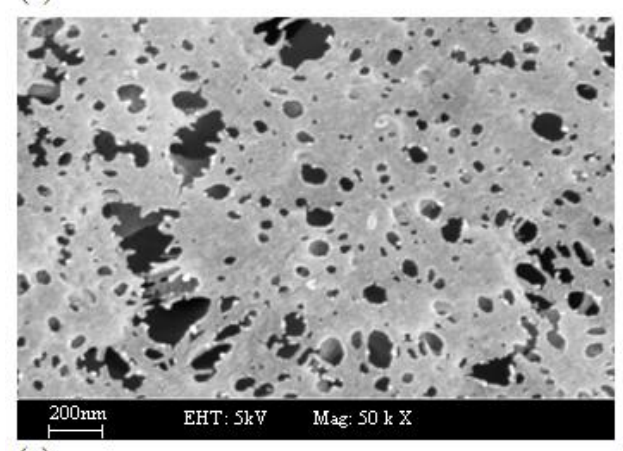

(c)

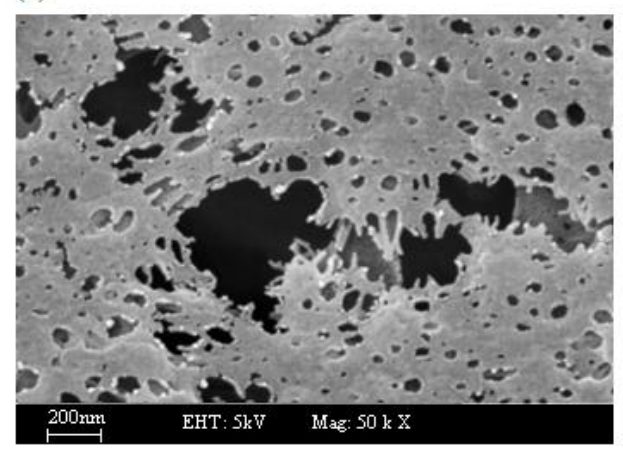

(b)

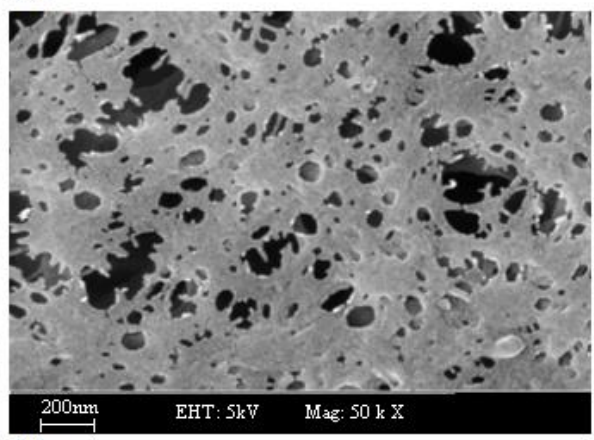

(d)

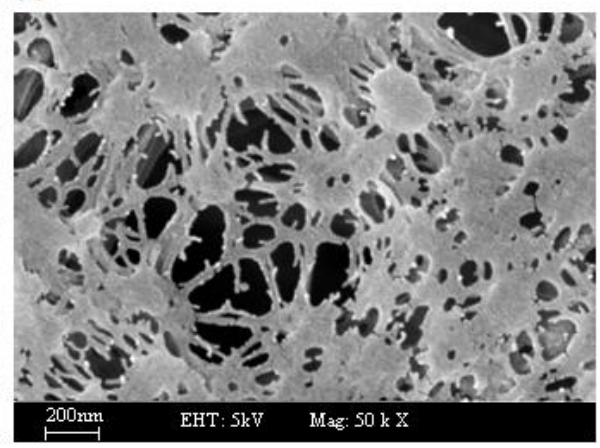

Figure 1. FESEM images of (a) untreated membrane and membranes treated for 3 hours at room temperature with (b) $0.2 \mathrm{M} \mathrm{KOH}$ (c) $0.2 \mathrm{M} \mathrm{NaOH}$ and (d) $0.2 \mathrm{M} \mathrm{NaOCl}$ with 50k magnifications.

\subsection{Tensile testing}

The alteration in mechanical properties of PVDF membrane was analysed based on elongation at break. In this study, elongation at break is represented by nominal elongation, described as a percentage ratio between the elongations of untreated membrane to treated membrane. This parameter is chosen as it shows the membrane flexibility and brittleness. Flexible membrane can withstand an imposed pressure for a longer stretch compared to brittle sample that could easily fracture. In general, the treated membranes exhibit poor flexibility as the elongation was reduced. This result is consistent with previous literature where the decline in mechanical strength was detected following membrane treatment $[17,18]$. Since mechanical properties are related to the membrane morphology, polymer chain scission and weakening of interaction among molecules are the possible reasons explaining why membrane is easily cracked when same amount of stress is applied [19]. In addition, a study by Causserand et al. (2008) indicated that a small number of chain scissions have a significant impact on the elongation and tensile strength at break point of the membrane material, in which for less than 2.8 $\%$ of chain scissions would resulted in a $80 \%$ loss in elongation at break point [20].

\subsubsection{Effects of temperature, treatment time and concentrations}

As shown in Figures 2 and 3, the nominal elongation was reduced following treatment with chemicals. With a temperature elevation and longer treatment time, the changes became more significant, particularly when using $0.2 \mathrm{M}$ of chemicals. Referring to 30 minutes $\mathrm{NaOCl}$ treatment in Figures 2(a) and 3(a), nominal elongation were reduced to around $73 \%$ and $68 \%$ following a treatment at room temperature and $45{ }^{\circ} \mathrm{C}$, respectively. A more remarkable reduction in nominal 
elongation, $67 \%$ for membrane treated in room condition and $61 \%$ at higher temperature were measured once treatment time is extended as shown in Figures 2(b) and 3(b), respectively. Overall, the higher alkaline concentration and higher temperature fasten the membrane degradation process.
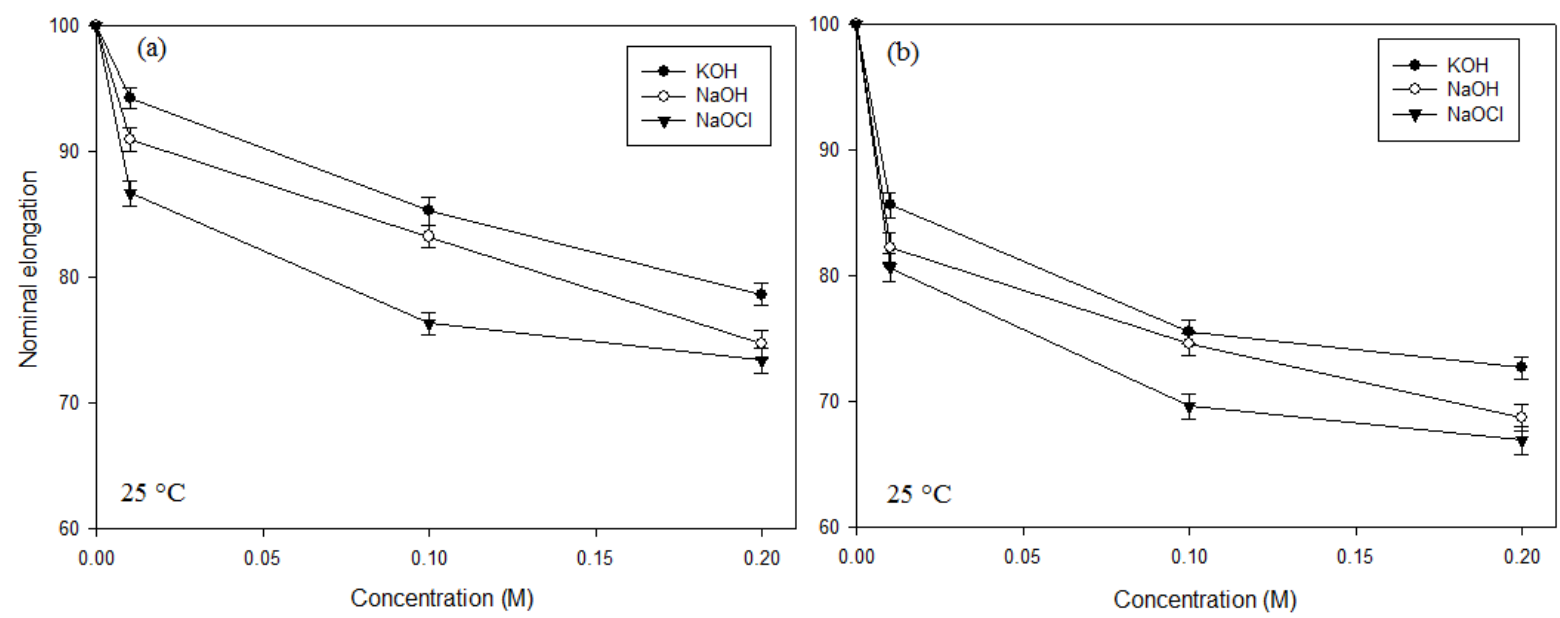

Figure 2. Nominal elongation for membrane treated at room temperature in different alkaline solution concentration for (a) 30 minutes and (b) 180 minutes.
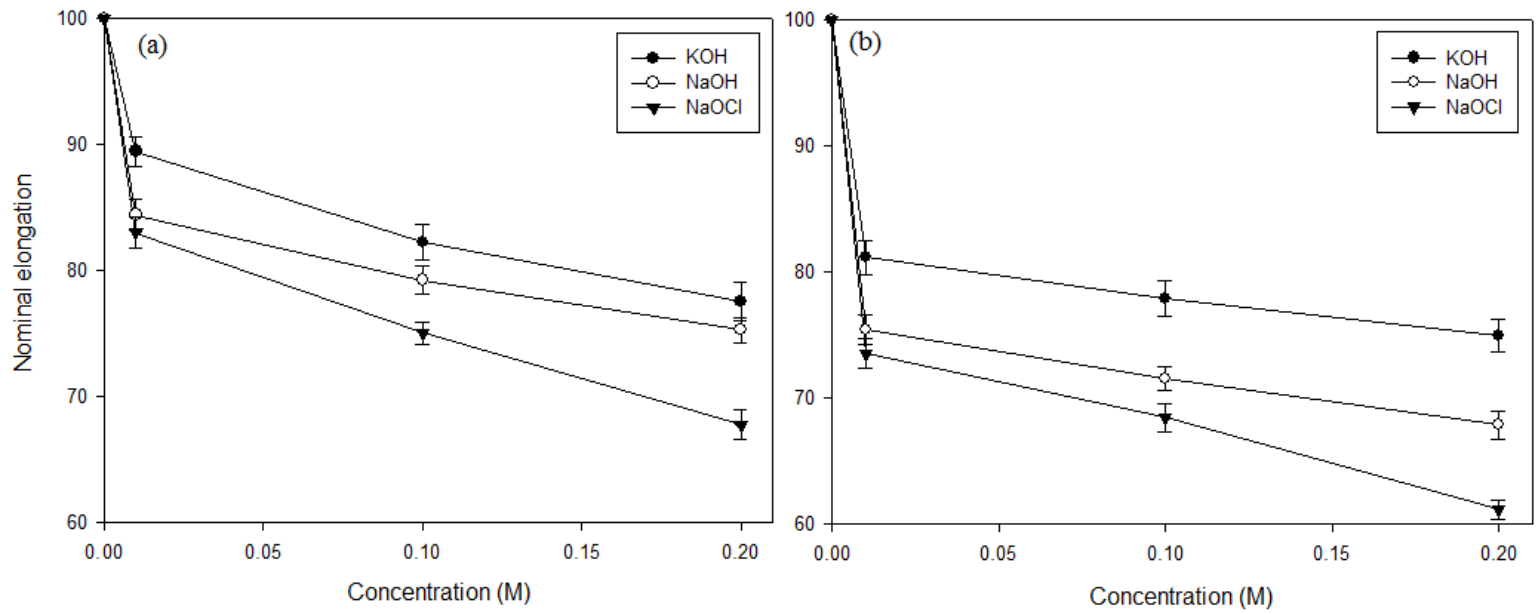

Figure 3. Nominal elongation for membrane treated at $45{ }^{\circ} \mathrm{C}$ in different alkaline solution concentration for (a) 30 minutes and (b) 180 minutes.

\subsubsection{Effects of chemicals}

It is evident that treatment with $\mathrm{NaOCl}$ has resulted in the most drastic effect on PVDF membrane stability in terms mechanical properties, followed by $\mathrm{NaOH}$ and $\mathrm{KOH}$. Direct contact with these chemicals has caused the membrane to exhibit lower nominal elongation. Generally, in hotter treatment solution, the membrane was constantly attacked by the chemical solution as further reduction in nominal elongation was observed. Membrane degradation caused by $\mathrm{NaOH}$ and $\mathrm{KOH}$ is mainly due to hydroxide ions attack on the polymer backbone. In comparison, the $\mathrm{NaOCl}$ treatment towards PVDF membrane results in the most severe degradation and it could be explained by its high oxidising properties. Two types of radicals formed from $\mathrm{NaOCl}$ were believed to accelerate the membrane structural changes compared to only one type of hydroxide radical originated from hydroxide solution. Further discussion of PVDF membrane degradation is explained in section 3.7. 


\subsection{Surface area of membrane}

Another important aspect to be analysed when examining material stability is to measure its specific surface area. It is known that reaction regularly occurred at the surface of materials. Thus, any modifications upon treatment on the specific surface area are another essential characteristic to be studied. The surface area is one of the major factors to determine the separation efficiency. The greater surface area gives rise to higher gas/liquid or liquid/liquid contact area and thus results in a higher absorption rate. In this work, a constant concentration of $0.2 \mathrm{M}$ of each solution was employed for membrane treatment. The BET surface area of untreated membrane is measured to be $4.22 \mathrm{~m}^{2} \mathrm{~g}^{-1}$.

As depicted in Figure 4, all treated membranes were found to exhibit lower surface area than the surface area of untreated membrane. The higher chemical concentration was observed to cause a more severe reduction in the specific surface area. This reduction in surface area can be explained by the alteration in the membrane pore size. To relate the surface area with pore size, the obtained FESEM images indicated that all treated membranes exhibit larger pore sizes. Accordingly, it could be presumed that the surface area of the membrane is inversely proportional to the pore size. This finding provides fundamental knowledge on membrane separation process as it indicates the lesser contact surface area once membrane in contact with alkaline solution. The reduction in membrane surface area will therefore result in poor separation.

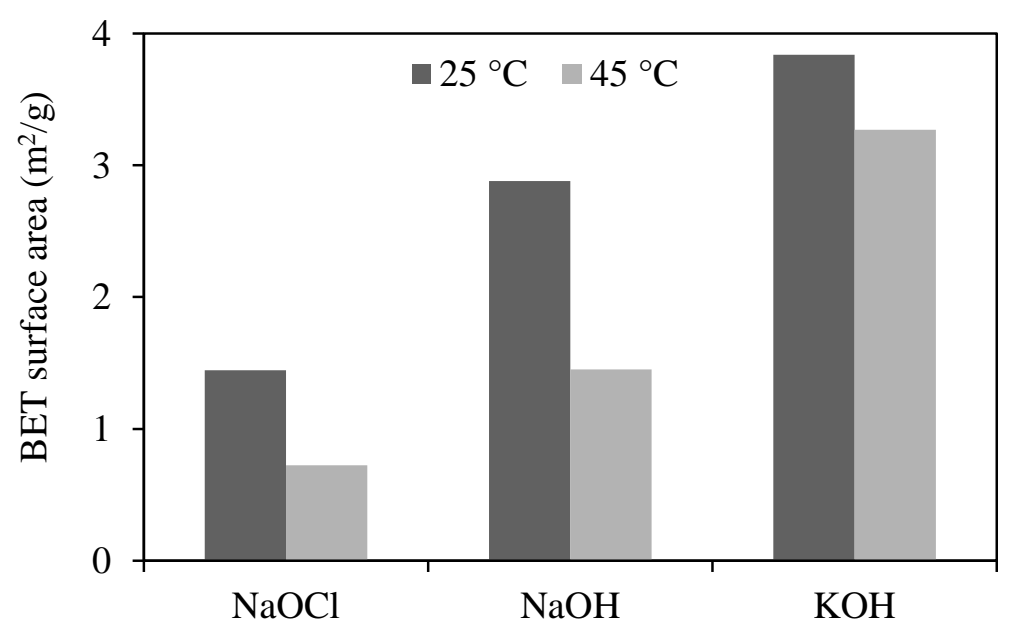

Figure 4. BET surface area of membranes after chemical treatment.

\subsubsection{Effects of chemicals}

$\mathrm{NaOCl}$ treated membrane exhibits a sharp reduction in the surface area, followed by the membrane exposed to $\mathrm{NaOH}$ and lastly $\mathrm{KOH}$. Membranes immersed in $\mathrm{NaOCl}$ at both low and high temperatures showed a reduction of more than half of the untreated membrane surface area. This indicated that the oxidant treated membrane has undergone the most severe surface damage compared to the other two chemicals. The overall trend obtained in this analysis is in a good agreement with the other analysis.

\subsection{DSC analysis}

The untreated membrane has a melting temperature of $164.3{ }^{\circ} \mathrm{C}$ (referred as a vertical line in the thermograms). The melting temperature of treated membranes was compared with this reference line. This thermal analysis study was based on examining the fluctuation in melting point as it 
indicates the temperature at which the regions of crystalline polymer melt. Since crystal structure of membrane plays the foremost role in affecting other properties as well, its thermal stability needs to be investigated. For instance, in the treatment of flue gas with membrane contactor, the membrane is exposed to a high temperature operation and thus its effects onto the membrane itself has become a matter of concern.

\subsubsection{Effect of temperature, treatment time and concentration}

From Figure 5, there was no considerable changes in melting point following treatment at room temperature. However, prolonged treatment duration and increment in treatment temperature has resulted in a more significant difference as the curve shifted to the left side of the reference line, corresponded to the reduced melting point. This trend is most notably demonstrated by $\mathrm{NaOCl}$ treated membrane where its melting point decreased to $161.22{ }^{\circ} \mathrm{C}$ and $161.06{ }^{\circ} \mathrm{C}$ after treatment with $0.01 \mathrm{M}$ and $0.2 \mathrm{M}$, respectively. This signifies that the declination in melting point of PVDF membrane was greatly influenced by the harsh environment (i.e. high concentration and high temperature). The good thermal stability of PVDF is due to strong C-F bonds and high electronegativity of $F$ atoms, leading to the formation of highly stable fluoropolymers compared to hydrocarbon polymers [21].
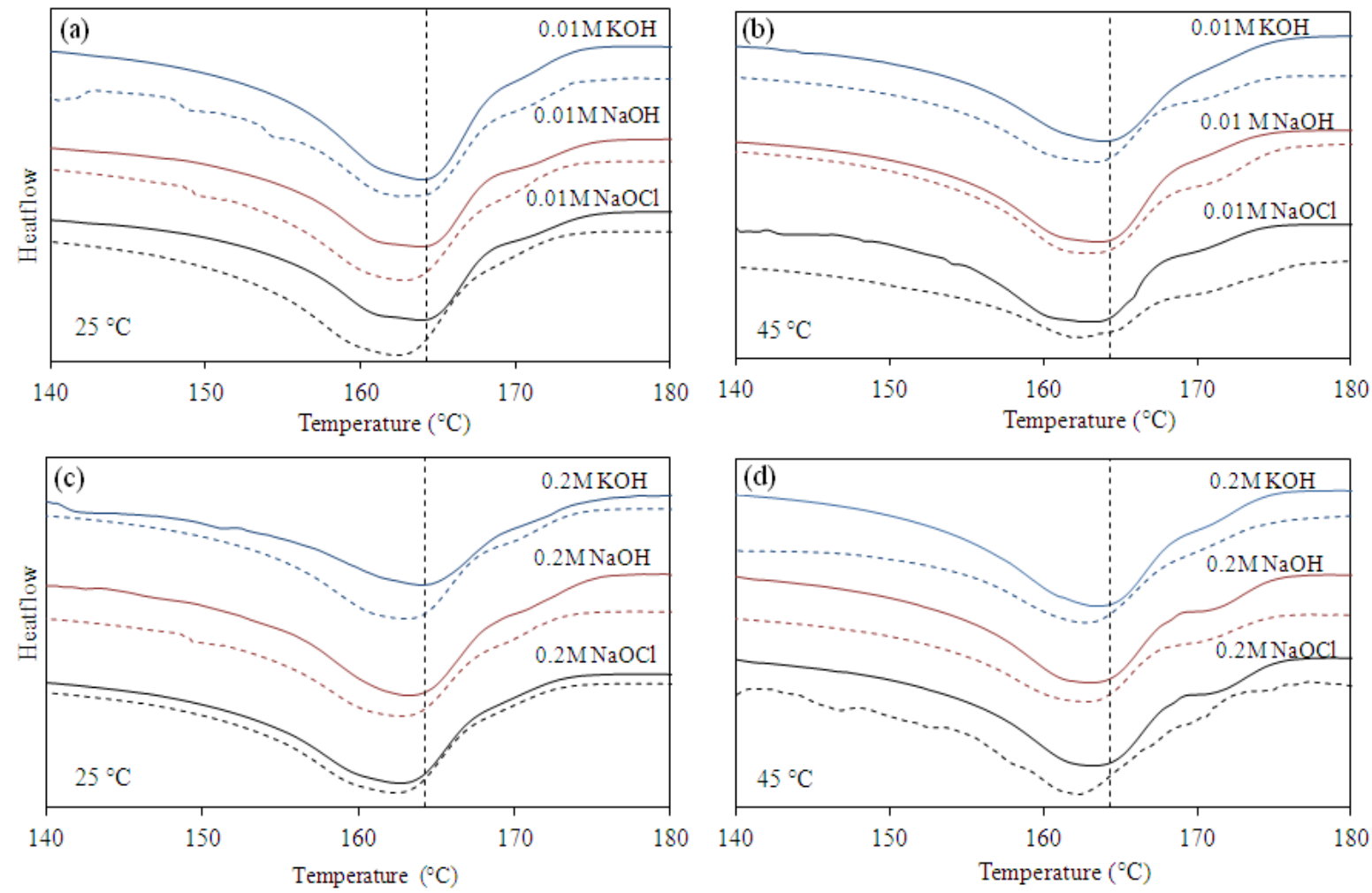

Figure 5. DSC thermograms of membranes treated in (a) $0.01 \mathrm{M}$ at $25^{\circ} \mathrm{C}$, (b) $0.01 \mathrm{M}$ at $45{ }^{\circ} \mathrm{C}$, (c) 0.2 $\mathrm{M}$ at $25{ }^{\circ} \mathrm{C}$ and (d) $0.2 \mathrm{M}$ at $45^{\circ} \mathrm{C}$; solid line and dashed line for 30 and 180 minutes, respectively.

\subsubsection{Effect of chemicals}

Overall, the $\mathrm{NaOCl}$ treated membranes demonstrated the noteworthy changes in melting point. In comparison, the membranes treated in $\mathrm{NaOH}$ and $\mathrm{KOH}$ exhibit minor changes in their melting point. This finding showed that $\mathrm{NaOCl}$ (oxidizing agent) acts more vigorously than $\mathrm{NaOH}$ and $\mathrm{KOH}$ (base solutions) in attacking the crystal structure of the membrane, resulting in a more severe degradation. Besides, modification of thermal properties of PVDF was linked to the dehydrofluorination process $[3,22]$. Details on the degradation mechanism is discussed in Section 3.7. 


\subsection{Membrane surface analysis}

The changes in the membrane surface chemistry were detected using Fourier transform infrared (FTIR). PVDF characteristic bands are typically observed at 761, 795, 872, 973, 1067 and $1180 \mathrm{~cm}^{-1}$ ascribed to $\alpha$-phase while 1276 and $1403 \mathrm{~cm}^{-1}$ ascribed to $\beta$-phase [18]. In addition, band at $839 \mathrm{~cm}^{-1}$ is corresponds to the amorphous phase of polymer [23]. PVDF membrane employed in this study is consisting mainly $\alpha$-phase. Figures 6 and 7 demonstrate the spectra for untreated and treated membrane by $0.2 \mathrm{M}$ of solutions at room temperature for 3 hours.

\subsubsection{Spectra analysis (finger print region)}

From Figure 6, the peak of $722 \mathrm{~cm}^{-1}$ is disappeared after treatments while the peaks of 1337 $\mathrm{cm}^{-1}$ started to appear very weakly after membrane treatments. A small peak at $722 \mathrm{~cm}^{-1}$ assigned to the $\mathrm{CH}_{2}$ rocking which occurred when there are at least four $-\mathrm{CH}_{2}-$ groups in a chain [24]. Since this band was disappeared in the spectra of treated membranes, it indicates that $\mathrm{CH}_{2}$ groups in a chain were reduced. In other words, the polymer chain scissions take place, thus the initial long polymer chain has been "cut" into shorter chain with the $\mathrm{CH}_{2}$ group of less than four. Therefore, it further assures the explanation suggested for deterioration in mechanical properties caused by polymer scission. For the very weak bands at $1338 \mathrm{~cm}^{-1}$, it can be attributed by the polymer chain defects, caused by head to head and tail to tail linkages [25].

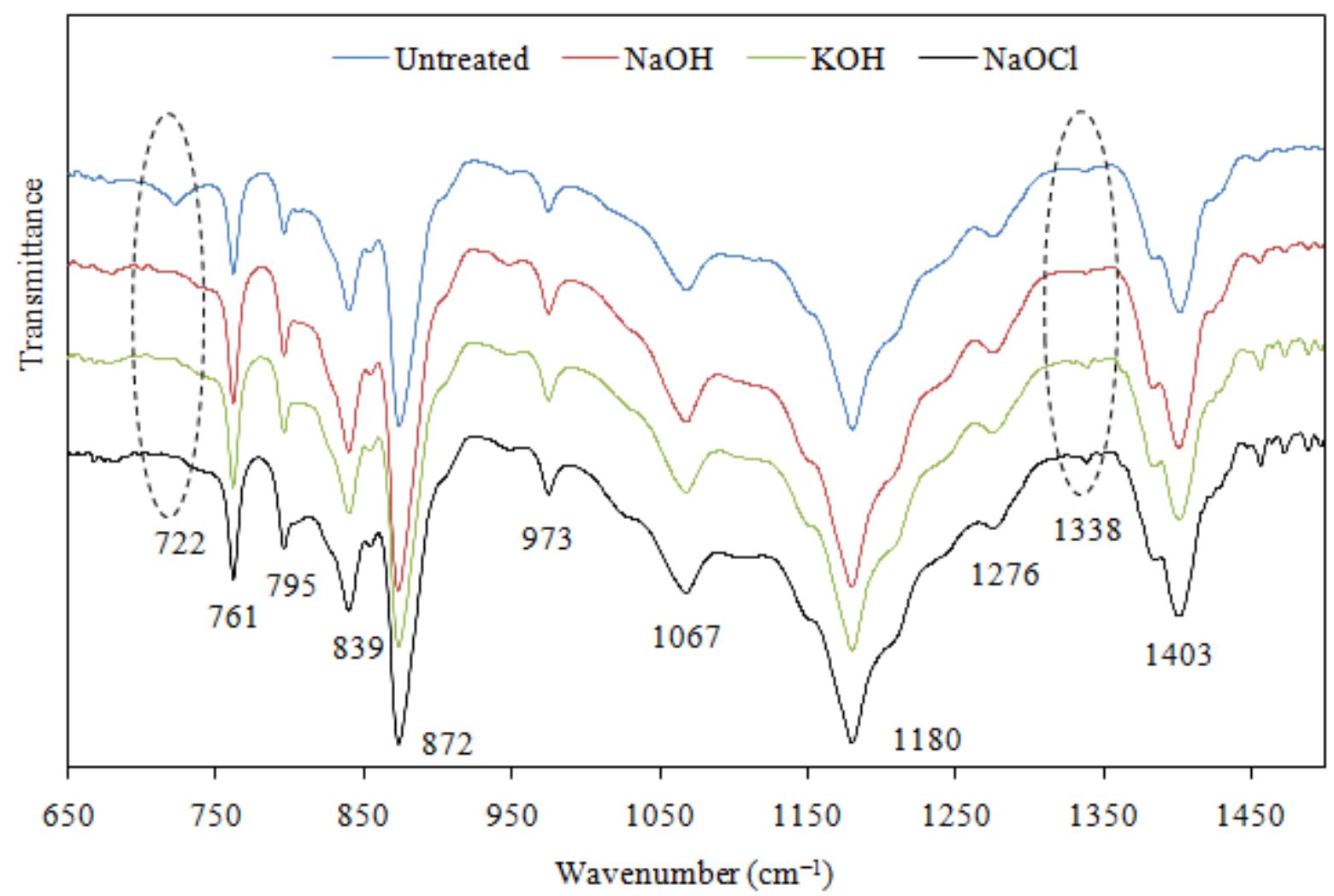

Figure 6. ATR-FTIR spectra from 650 to $1500 \mathrm{~cm}^{-1}$. 


\subsubsection{Spectra analysis (double and triple bond region)}

The occurrence of dehydrofluorination process can be determined from FTIR spectra at the peaks of $1650 \mathrm{~cm}^{-1}$, ascribed to $\mathrm{C}=\mathrm{C}$ double bond and $1700-1800 \mathrm{~cm}^{-1}$, ascribed to $\mathrm{C}=\mathrm{O}$ carbonyl bond. As depicted in Figure 7, both of these bands are however not clearly detected. This could be due to the presence of atmospheric water vapour in the path of infrared beam from source to detector. It tends to mask some of the spectra absorbance. Additionally, according to Ross et al. (2000), $\mathrm{C}=\mathrm{C}$ double bond is not active in infrared but Raman active [9]. Therefore, to mitigate this problem, the membrane should be vacuum dried prior to the analysis to remove any interference of water vapour. Analysis by FT-Raman is also recommended to verify the formation of $\mathrm{C}=\mathrm{C}$ double bonds. This is crucial to identify whether dehydrofluorination process would occur under mild treatment conditions (i.e. low temperature, low concentration and shorter time). In this particular study, the absence of those peaks could be caused by the mild treatment conditions without temperature elevation. On the other hand, there is a small peak at $2357 \mathrm{~cm}^{-1}$ that appears following $\mathrm{KOH}$ and $\mathrm{NaOCl}$ treatment. According to Feng et al., this band is assigned to the strength vibration of $\mathrm{C} \equiv \mathrm{C}$ triple bond [26]. The obtained spectra indicated that the membrane surface chemistry did not change considerably. Nevertheless, it is worth to note that the degradation on PVDF membrane could not only occur on the surface but also in the inner layer as well.

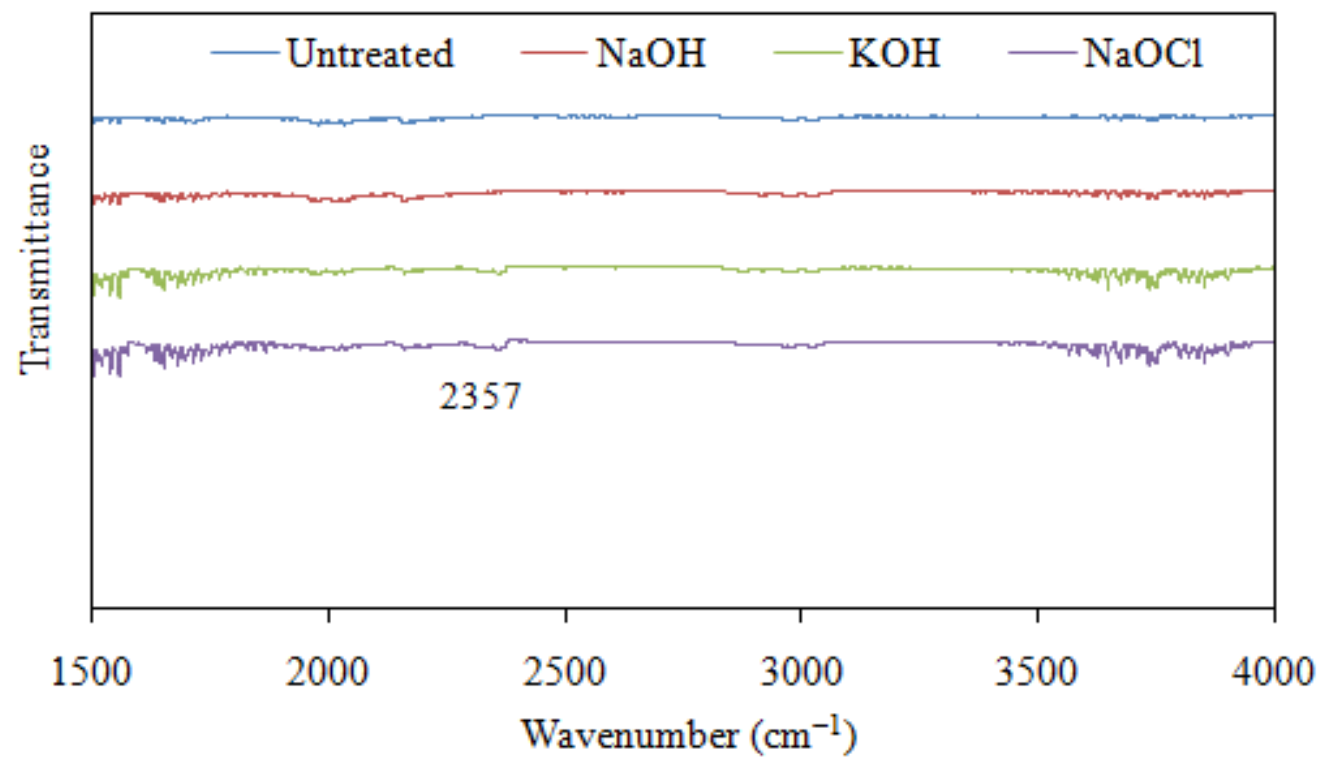

Figure 7. ATR-FTIR spectra from 1500 to $4000 \mathrm{~cm}^{-1}$.

\subsection{Water flux and contact angle measurement}

The increment in water flux is determined by the difference between the flux of untreated PVDF membrane and the flux of the treated membranes. As can be seen in Figure 8 and 9, the pure water flux becomes higher subsequent to chemical treatment. The measured contact angle for untreated PVDF membrane was $103.10 \pm 1.76^{\circ}$ and it was found that all treated membranes exhibit lower contact angle values. This finding indicated the membrane has become less hydrophobic following the exposure to chemicals. It can be observed that the lower the contact angle, the higher the flux increment. 

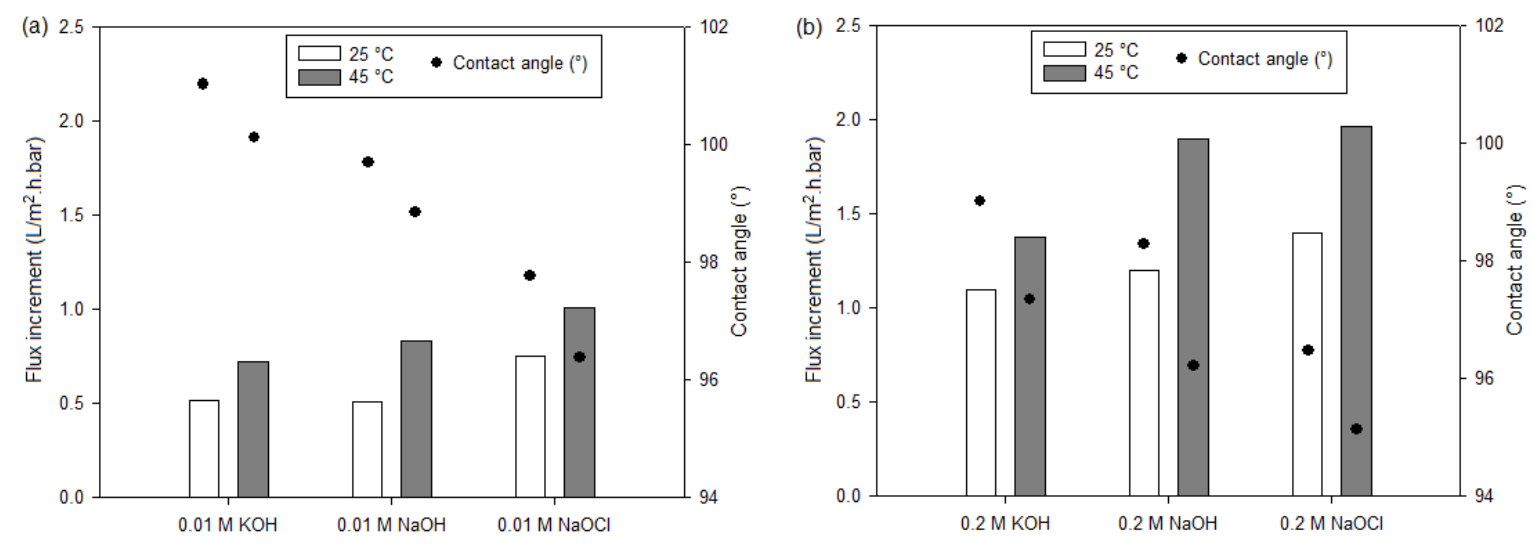

Figure 8. Flux increment and contact angle for membrane treated for 3 hours at different temperature in (a) $0.01 \mathrm{M}$ and (b) $0.2 \mathrm{M}$ alkaline solution concentration.

\subsubsection{Effect of temperature, treatment time and concentrations}

In general, it is shown that temperature elevation and treatment time extension has resulted in a higher flux increment for the treated membranes. However, by comparing the membranes treated in different concentration of alkaline solution, there is a clear variation between the low and high concentration treatment. For membrane treated at different temperature with any of the $0.01 \mathrm{M}$ of alkaline solution, only a slight difference in flux increment was measured. A similar trend was observed for a prolong treatment time at room temperature where results showed that the membranes treated at constant concentrations exhibit small flux increment. Nevertheless, when using a higher concentration, an obvious flux increment was measured, particularly at higher treatment temperature. This indicates that concentration is a dominant factor for the alteration in membrane water flux compared to temperature and time. In addition, these findings were crucial as it reveals that PVDF membranes were started to be attacked by hydroxide ions even at mild condition.
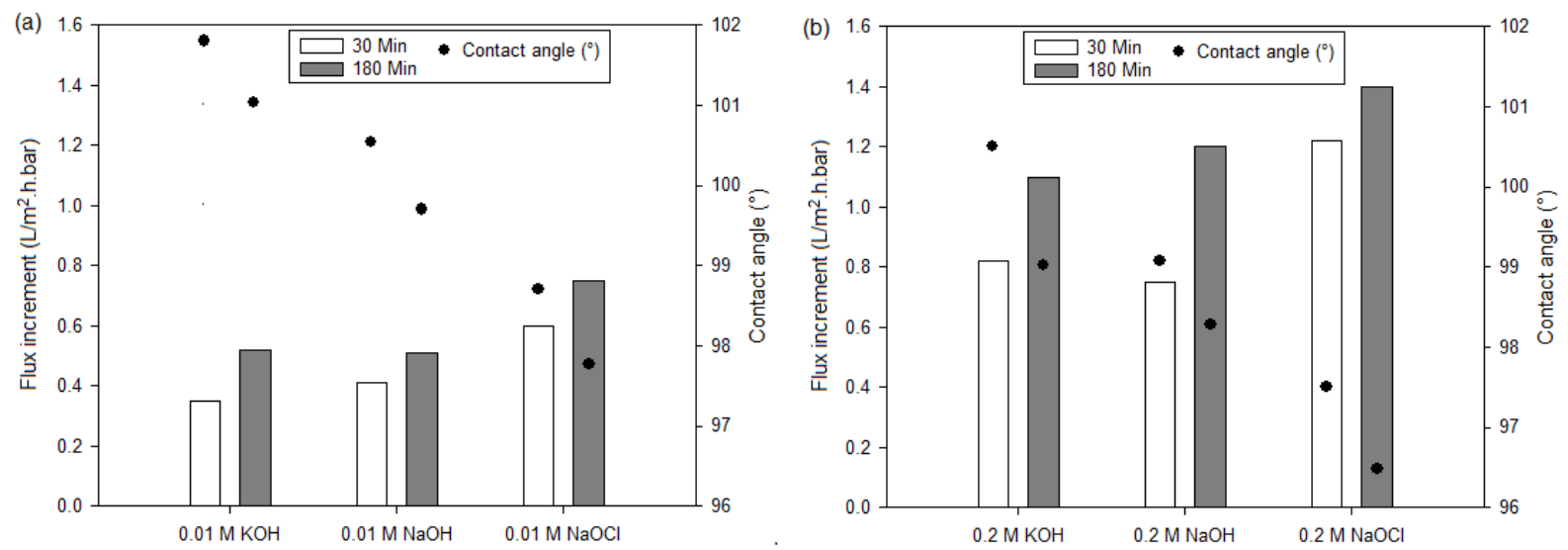

Figure 9. Flux increment and contact angle for membrane treated at room temperature for different treatment time in (a) $0.01 \mathrm{M}$ and (b) $0.2 \mathrm{M}$ alkaline solution concentration. 


\subsubsection{Effect of chemicals}

Generally, it can be observed that among the three chemicals used, $\mathrm{KOH}$ results in the lowest flux increment, followed by $\mathrm{NaOH}$ and $\mathrm{NaOCl}$. Compared to membranes soaked in the strong alkaline solutions of $\mathrm{NaOH}$ or $\mathrm{KOH}$, membrane treated in $\mathrm{NaOCl}$ (a strong oxidant) showed the highest flux increment. Flux increment could be attributable to not only because of pore enlargement, but it might as well caused by the increased membrane hydrophilicity, as shown by the reduced contact angle values $[14,15,26]$. NaOCl treated membrane exhibit highest increment in flux, which could be explained by its high oxidizing ability that cause a PVDF membrane to be more hydrophilic, hence give rise to a better flux permeability.

\subsection{Assessment of PVDF degradation}

It is reported that the changes in PVDF membrane properties following the exposure to chemical is attributable to the dehydrofluorination process [18]. To date, there are several works that have been done to study the degradation mechanism of PVDF caused by the alkaline treatment [9-12]. One of the possible mechanism is proposed by Ross et al. (2000), as depicted in Figure 10.
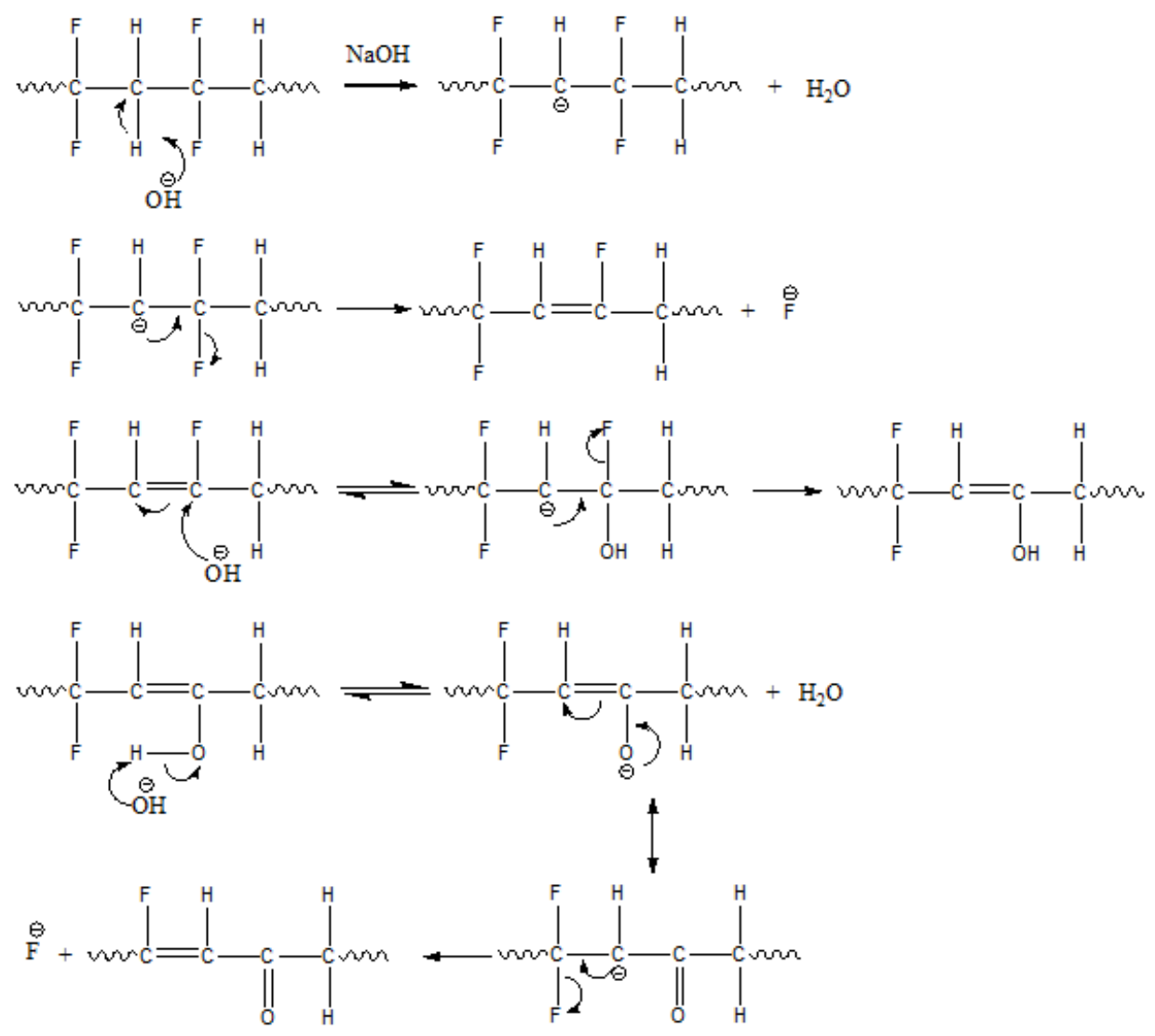

Figure 10. Degradation mechanism of PVDF.

On the other hand, the PVDF degradation by $\mathrm{NaOCl}$ was alleged to be attributable to the existence of radicals and its high oxidizing properties. Hypochlorite form different types of radicals and the proposed mechanism by earlier work [27] is as follows:

$\mathrm{HClO}+\mathrm{ClO}^{-} \rightarrow \mathrm{ClO}^{-}+\mathrm{Cl}^{-}+\mathrm{OH}^{\circ}$ 


$$
\begin{aligned}
& \mathrm{OH}^{-}+\mathrm{ClO}^{-} \rightarrow \mathrm{ClO}^{-}+\mathrm{OH}^{-} \\
& \mathrm{Cl}^{-}+\mathrm{ClO}^{-}+\mathrm{OH}^{-} \rightarrow 2 \mathrm{Cl}^{-}+\mathrm{O}_{2}+\mathrm{OH}^{\circ}
\end{aligned}
$$

The overall reaction:

$$
2 \mathrm{HClO} \rightarrow 2 \mathrm{OH}^{\circ}+\mathrm{Cl}_{2}
$$

The formation of radicals $\left(\mathrm{OH}^{\cdot}\right.$ and $\left.\mathrm{ClO} \cdot\right)$ was believed to cause more severe degradation on PVDF membrane compared to $\mathrm{NaOH}$ and $\mathrm{KOH}$, in which the hydroxide ion $\left(\mathrm{OH}^{-}\right)$, a very nucleophilic anion attacks polar bonds in inorganic and organic materials [3].

\section{Conclusion}

The stability of PVDF membrane in alkaline environment has been investigated. Effects of different chemicals on the intrinsic properties of PVDF membrane were investigated and studied. PVDF membranes treated using three different chemicals, $\mathrm{KOH}, \mathrm{NaOH}$ and $\mathrm{NaOCl}$ were characterised using several analytical methods. In general, the findings showed that the exposure to chemical cause a number of changes in membrane characteristics. All treated membranes exhibit increment in pore size, reduced mechanical properties, alterations in surface chemistry and a slight reduction in melting temperature. The most intriguing fact is that PVDF membrane properties were affected even for a short time chemical exposure using low concentration of chemicals. As a whole, $\mathrm{NaOCl}$ is determined to cause the most detrimental effects towards PVDF membrane, followed by $\mathrm{NaOH}$ and $\mathrm{KOH}$.

\section{Acknowledgements}

The author would like to thank the University of Malaya, Malaysia for financial support through UMRG120/11AET and PPP grant no: PV140 2012A, and special acknowledgement to the Ministry of Education Malaysia for providing SLAB scholarship.

\section{References}

[1] Liu, F., Hashim, N.A., Liu, Y., Abed, M.R.M., Li, K. (2011). Progress in the production and modification of PVDF membranes, Journal of Membrane Science, Vol. 375, No. 1-2, 1-27.

[2] Kang, G.-d. and Cao, Y.-m. (2014). Application and modification of poly(vinylidene fluoride) (PVDF) membranes - A review, Journal of Membrane Science, Vol. 463, 145-165.

[3] Rabuni, M.F., Sulaiman, N.M.N., Aroua, M.K., Hashim, N.A. (2013). Effects of alkaline environments at mild conditions on the stability of PVDF membrane: An experimental study, Industrial \& Engineering Chemistry Research, Vol. 52, No. 45, 15874-15882.

[4] Park, H.H., Deshwal, B.R., Jo, H.D., Choi, W.K., Kim, I.W., Lee, H.K. (2009). Absorption of nitrogen dioxide by PVDF hollow fiber membranes in a G-L contactor, Desalination, Vol. 243, No. 1-3, 52-64.

[5] Atchariyawut, S., Jiraratananon, R., Wang, R. (2007). Separation of $\mathrm{CO}_{2}$ from $\mathrm{CH}_{4}$ by using gas-liquid membrane contacting process, Journal of Membrane Science, Vol. 304, No. 1-2, 163-172.

[6] Ahmad, A.L., Sunarti, A.R., Lee, K.T., Fernando, W.J.N. (2010). $\mathrm{CO}_{2}$ removal using membrane gas absorption, International Journal of Greenhouse Gas Control, Vol. 4, No. 3, 495-498.

[7] Hajibabania, S., Antony, A., Leslie, G., Le-Clech, P. (2012). Relative impact of fouling and cleaning on PVDF membrane hydraulic performances, Separation and Purification Technology, Vol. 90, 204-212.

[8] Rabuni, M.F., Nik Sulaiman, N.M., Aroua, M.K., Yern Chee, C., Hashim, N. A. (2015). Impact of in situ physical and chemical cleaning on PVDF membrane properties and performances, Chemical Engineering Science, Vol. 122, 426-435.

[9] Ross, G.J., Watts, J.F., Hill, M.P., Morrissey, P. (2000). Surface modification of poly(vinylidene fluoride) by alkaline treatment1. The degradation mechanism, Polymer, Vol. 41, No.5, 1685-1696. 
[10] Zhao, X., Song, L., Fu, J., Tang, P., Liu, F. (2011). Experimental and DFT investigation of surface degradation of polyvinylidene fluoride membrane in alkaline solution, Surface Science, Vol. 605, No. 11-12, 1005-1015.

[11] Zhang, S., Shen, J., Qiu, X., Weng, D., Zhu, W. (2006). ESR and vibrational spectroscopy study on poly(vinylidene fluoride) membranes with alkaline treatment, Journal of Power Sources, Vol. 153, No. 2, 234-238.

[12] Ross, G.J., Watts, J.F., Hill, M.P., Morrissey, P. (2001). Surface modification of poly(vinylidene fluoride) by alkaline treatment Part 2. Process modification by the use of phase transfer catalysts, Polymer, Vol. 42, No. 2, 403-413.

[13] Rabuni, M.F., Nik Sulaiman, N.M., Hashim, N. A. (2015). A systematic assessment method for the investigation of the PVDF membrane stability, Desalination and Water Treatment, 1-12.

[14] Levitsky, I., Duek, A., Arkhangelsky, E., Pinchev, D., Kadoshian, T., Shetrit, H., Naim, R., Gitis, V. (2011). Understanding the oxidative cleaning of UF membranes, Journal of Membrane Science, Vol. 377, No. 1-2, 206-213.

[15] Wang, P., Wang, Z., Wu, Z., Zhou, Q., Yang, D. (2010). Effect of hypochlorite cleaning on the physiochemical characteristics of polyvinylidene fluoride membranes, Chemical Engineering Journal, Vol. 162, No. 3, 1050-1056.

[16] Lang, W.-Z., Zhang, X., Shen, J.-P., Xu, H.-P., Xu, Z.-L., Guo, Y.-J. (2014). The contrastive study of chemical treatment on the properties of PVDF/PFSA and PVDF/PVP ultrafiltration membranes, Desalination, Vol. 341, 72-82.

[17] Arkhangelsky, E., Kuzmenko, D., Gitis, N.V., Vinogradov, M., Kuiry, S., Gitis, V. (2007). Hypochlorite Cleaning Causes Degradation of Polymer Membranes, Tribol Lett, Vol. 28, No. 2,109116.

[18] Hashim, N.A., Yutie Liu, K.Li, (2011). Stability of PVDF hollow fibre membranes in sodium hydroxide aqueous solution, Chemical Engineering Science, Vol. 66, No. 8, 1565-1575.

[19] Lovinger, A. J. (1982). Annealing of poly(vinylidene fluoride) and formation of a fifth phase, Macromolecules, Vol. 15, No. 1, 40-44.

[20] Causserand, C., Rouaix, S., Lafaille, J.-P., Aimar, P. (2008). Ageing of polysulfone membranes in contact with bleach solution: Role of radical oxidation and of some dissolved metal ions, Chemical Engineering and Processing: Process Intensification, Vol. 47, No. 1, 48-56.

[21] O'Hagan, D. (2008). Understanding organofluorine chemistry. An introduction to the C-F bond, Chemical Society Reviews, Vol. 37, No. 2, 308-319.

[22] Nguyen, T. (1985). Degradation of Poly(vinyl Fluoride) and Poly(vinylidene Fluoride), Journal of Macromolecular Science, Part C: Polymer Reviews, Vol. 25, No. 2, 227-275.

[23] Aravindan, V., Vickraman, P., Kumar, T.P. (2008). Polyvinylidene fluoride-hexafluoropropylene (PVdF-HFP)-based composite polymer electrolyte containing $\mathrm{LiPF}_{3}\left(\mathrm{CF}_{3} \mathrm{CF}_{2}\right)_{3}$, Journal of NonCrystalline Solids, Vol. 354, No. 29, 3451-3457.

[24] Shurvell, H.F., (2006). Spectra- Structure Correlations in the Mid- and Far-Infrared, in: Handbook of Vibrational Spectroscopy, John Wiley \& Sons, Ltd.

[25] Boccaccio, T., Bottino, A., Capannelli, G., Piaggio, P. (2002). Characterization of PVDF membranes by vibrational spectroscopy, Journal of Membrane Science, Vol. 210, No. 2, 315-329.

[26] Liu, Q.-F., Lee, C.-H., Kim, H. (2010). Performance Evaluation of Alkaline Treated Poly(vinylidene fluoride) Membranes, Separation Science and Technology, Vol. 45, No. 9,1209-1215.

[27] Wienk, I.M., Meuleman, E.E.B., Borneman, Z., van den Boomgaard, T., Smolders, C.A. (1995). Chemical treatment of membranes of a polymer blend: Mechanism of the reaction of hypochlorite with poly(vinyl pyrrolidone). Journal of Polymer Science Part A: Polymer Chemistry Vol. 33, No.1, 49-54. 


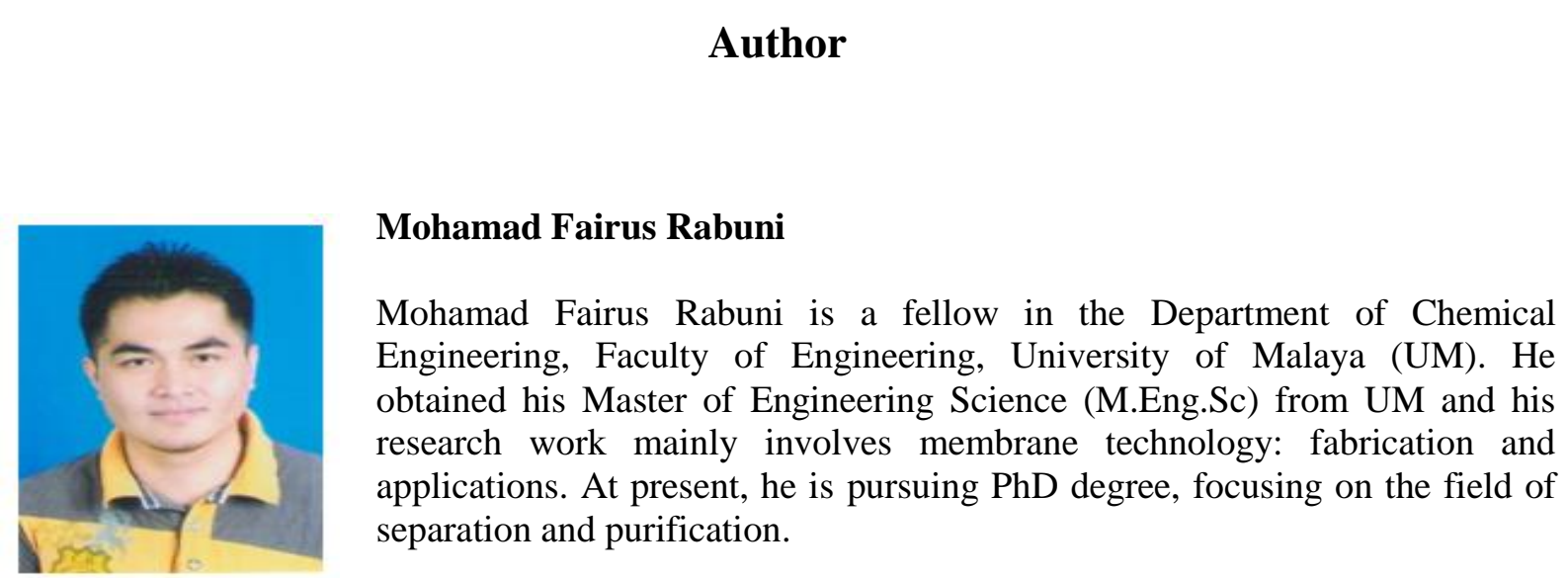

Author separation and purification. 